\title{
A Corpus-Based Contrastive Analysis of Stance Strategies in Native and Nonnative Speakers' English Academic Writings: Introduction and Discussion Sections in Focus
}

\author{
Milad Shirzadi ${ }^{1}$, Farzad Akhgar ${ }^{2}$, Amir Rooholamin $^{1}$, \& Sajad Shafiee ${ }^{3}$
}

1. Department of English, Khorasgan Branch, Islamic Azad University, Isfahan, Iran

2. Department of English, Shahreza Branch, Islamic Azad University, Shahreza, Iran

3. Department of English, Shahrekord Branch, Islamic Azad University, Shahrekord, Iran

Email: s.shafiee@iaushk.ac.ir

Received: July 17, 2017 Accepted: September 30, 2017 Online Published: December 20, 2017

\begin{abstract}
The present study was an attempt to illustrate the interaction between writers and readers. Conveying of the writers' voice, stance, and interaction with reader was put forward within this paradigm. Being a good academic writer is highly related to the use of these strategies. Adopting a position and persuading readers of claims are very important. This study was aimed at showing the differences between Iranian and American M.A. EFL writers in using stance strategies (hedges, boosters, attitude markers, and self-mentions) in Introduction and Discussion sections of academic papers. The corpora for this study were 40 articles (20 for American native and 20 for Iranian nonnative writers) from different journals such as Journal of Research Studies in Education, English language Teaching, System, TESOL Quarterly, and ELT. The significance and frequency of items were calculated using SPSS software version 22. Such statistical tools as frequency, percentage, and Chi-square were utilized to analyze the collected data. The findings showed that there was no statistically significant difference between native and nonnative writers in using stance strategies although native writers tended to use hedges, attitude markers, and self-mentions comparatively more than nonnatives, whereas nonnative writers used a greater number of boosters.
\end{abstract}

Keywords: attitude markers, boosters, hedges, self-mentions, stance strategies, native vs. nonnative writers

\section{Introduction}

As deemed preponderant for a writer to reveal his/her degree of involvement in a text, this will exert a profound effect on the reader when the text has a good interaction with him. Such interactions, indeed, are conveyed via certainty, beliefs, degree of risk taking, and claims of a writer. Inextricably linked with this is stance, a model of interaction put forward by Hyland (2005) by the name of Stance and Engagement. Despite its broader implications in different contexts, the one which is the direct focus of this study concerns itself with only stance defined by Hyland as how 'writers intrude to stamp their personal authority onto their arguments or step back and disguise their involvement'. In other words, stance expresses a textual 'voice' or community recognized personality. He also goes on to say that stance can be seen as an attitudinal dimension and includes features which refer to the ways writers present themselves and convey their judgments, opinions, and commitments. Hyland subcategorizes them as hedges, boosters, attitude markers, and self-mention (See Table 1).

To accomplish a successful writer-reader interaction, a writer should take account of readers' personal traits, their background knowledge, processing constraints, and recognition of face needs of readers (Myers, 1989). 


\section{International Journal of Research in English Education}

Table 1. Hyland's model of interaction (2005)

Interaction

\begin{tabular}{llll}
\hline \multicolumn{2}{l}{ Stance } & \multicolumn{2}{l}{ Engagement } \\
\hline 1 & Hedges & 1 & Reader Pronouns \\
$2 \quad$ Boosters & 2 & Directives \\
3 & Attitude Marker & 3 & Questions \\
4 & Self-Mention & 4 & Shared Knowledge \\
& & 5 & Personal Aides \\
\hline
\end{tabular}

In what follows, a more detailed description of each of these strategies is presented.

\subsection{Hedges}

Such expressions as doubt and certainty are collectively known as hedges and boosters (Holmes, 1984, 1990). Hedges such as might, probably and seem signal a tentative assessment of referential information and convey collegial respect for the views of colleagues. Indeed, hedging can be defined as a tentative language to avoid any certainty or to mitigate the statements to able to avert possible criticism. Either you use it to distinguish facts from opinion, or "honesty, modesty, and proper caution" (Swales, 1990, p.174). To put it differently, hedges indicate the writer's decision to withhold complete commitment to a proposition, allowing information to be presented as an opinion rather than accredited fact (Ken Hyland, 2005). Boosters, on the other hand, allow writers to express conviction and to mark their involvement and solidarity with an audience (Hyland, 1998a\&b; Myers, 1989).

A definite aid of using hedges and boosters is to satisfy and convince the readers about the claims that they advance. Such devices help academics gain acceptance for their work by balancing conviction with caution, and by conveying an appropriate disciplinary persona of modesty and assertiveness (Hyland, 1996a). In Hallidaian linguistics, three meta functions are considered to show some degrees of interactions with others, these meta functions are textual (in many texts discourse flow, information flow and logical are other names for this meta function), interpersonal and ideational (experiential). Hedges and boosters are facilitating the concepts of both interpersonal and ideational metafunctions. In spoken utterances and written sentences, hedges and boosters are to many extents utilizing the authorial judgments. Academic rhetorical writings are logically orientated via these strategies. Opinions, commitments, effective arguments, writing competences are successfully expressed by stance strategies. Interpersonal meaning conveying is specifically covered by stance strategies. Stance-support and stance-taking are actions and processes in which expository and academic essays are conducted. Argumentations in essays are also in a high degree of importance. Argument has been defined as "a textual structure characterized by propositions some of which are in the semantic relation of 'support' to others" (Shaw, 2000, p.41, as cited in van Dijk, 1988).

\subsection{Boosters}

Boosters are words like clearly, obviously, highly, and in fact, allowing writers to express their certainty in what they say and to mark involvement with the topic and solidarity with their audience. They are essentially deployed to stress shared information, group membership, and engagement with readers (Hyland, 1999).

Salager-Meyer (1997) view the term "boosters" as those lexical items by means of which the writer can show strong confidence for a claim. Hyland (1998a; 2005) shares the same view believing that one can make their claim powerful by using booster expressions. 


\section{International Journal of Research in English Education}

\subsection{Attitude Markers}

Attitude markers indicate the writer's affective, as distinct from epistemic, attitude to propositions, conveying surprise, agreement, importance, frustration, and so on, rather than commitment. While attitude is expressed throughout a text by the use of subordination, comparatives, progressive particles, punctuation, text location, and so on, it is most explicitly signaled by attitude verbs (e.g., agree, prefer), sentence adverbs (unfortunately, hopefully), and adjectives (appropriate, logical, remarkable) (Hyland, 2005). To illustrate more, attitude markers such as unfortunately, strongly, elegant, remarkably, instructively, helpfully, and quite extraordinary are known to enable writers to express their attitude towards a linguistic production in both spoken and written forms. For better clarification, attitude markers such as unfortunately, strongly, elegant, remarkably, instructively, helpfully, quite extraordinary, bad, important, straight forward, etc are to name but a few.

The writer's attitude towards and feeling about an issue, event, or person, referred to as "attitudinal stance" in Conrad and Biber's work (2000, p.57). The author's degree of involvement, the probability or certainty of an event in a writing project or the truth of an utterance in domain of semantics is totally connected with Halliday's "modality." In functionalism, S.F.G (systemic functional grammar) proves that every instance of a proposition is a sociocultural and a socio pragmatic illocutionary act of interaction whereby stance strategies support this claim. There had been influential researches dealing with cross-linguistic and cross-cultural differences using stance features -mainly hedges and boosters - asserting socio-cultural or style differences among a variety of languages. Stance features have been analyzed in different fields and each highlighted the significance of interdisciplinary features within languages' persona to project both personal modesty and honesty (Salager-Meyer, 1994).

\subsection{Self-Mentions}

Self-mention (such as I, we, my, author, and our) refers to the use of first person pronouns and possessive adjectives to present propositional, affective, and interpersonal information (Hyland, 2001). Presence of the writers' identity, style, and interpersonal information (Hyland, 2001) could be achieved by this feature, which, of course, is occasionally avoided intentionally by some academics in order not to create any misunderstanding or they suppose that one should use passive verbs as much as they afford to be accepted by discourse community members and their voice could be heard by the whole study's outcomes adopting disciplinary-situated authorial identity (Hyland, 2005).

As the right strategies to gain acceptance, certainty, and avoidance of certain responsibility, stance and engagement features have been explored in different domains and disciplines in few studies (Hyland, 2000, 2005). In addition, most studies conducted concentrate on the differences between two different fields of the academic writings while using stance and engagement strategies according to Hyland model (2005), for example in Biology and linguistics. However, to the authors' best knowledge, very few publications are available in the literature that deal with the difference between native and nonnative writers in just one field of the study like in TEFL, applying the Hyland's model.

\section{Review of the Literature}

Blagojevic (2004) conducted a study with a view to observing the differences between English native and non-native speakers. The result of his study revealed no statistically significant difference in the use of metadiscourse markers across the selected disciplines. Another pertinent study was undertaken by Abdi (2002) focusing on the type and application of MDMs (meta-discourse markers: hedges, emphatics, and attitude-markers) in 2 majors: Social Science (SS) and Natural Sciences (NS). The results showed a statistically significant difference between the two majors. In a different yet relevant study, Rashidi and Alihosseini (2012) examined the difference in the use and frequency of metadiscourse markers in the abstracts of 20 research articles in the field of sociology and engineering. The obtained results revealed no statistically significant difference in the use of metadiscourse markers across the selected disciplines. Atai and Sadr's (2008) study showed a statistically significant difference in the use of hedging markers in the academic writings of English native and non-native speakers in applied linguistics research studies. Furthermore, in Ansarian and Tarlani's (2011) study, the results showed significant differences in the way native Persian and English represent their readers. Also, considerable differences were observed in categorical distribution of reader engagement markers (Ansarian \& Tarlani, 2011). The present study thus made an attempt to answer the following research questions: 


\section{International Journal of Research in English Education}

- What is frequency and percentage of use of stance strategies (hedges, boosters, attitude markers, and selfmentions) by American native and Iranian nonnative writers?

- $\quad$ Is there any significant difference between Iranian and American M.A EFL writers in using stance strategies (hedges, boosters, attitude markers, and self-mentions) in Introduction and Discussion sections of the academic papers?

In addition to L1/L2 comparisons, other research has compared stance taking patterns in student writing at different stages of development within a discipline (Coffin, 2002; Hewings, 2004), as well as differential patterns among students from different disciplines (North, 2005). Coffin's (2002) analysis of students' history writing reveals a developmental path whereby students are implicitly expected to move from (using Coffin's terms) a "recorder" to an "interpreter" of history and finally to an "adjudicator" of historical discourses. The more advanced adjudicator voice is characterized by frequent use of discoursal resources-for example, attributions, concessions, counters-to negotiate solidarity with a reader who is projected to hold contrary points of view.

Related research has also shown that, while students are often encouraged to take a "critical" stance with regard to others' arguments, a highly attitudinal, forceful, and assertive stance is less valued in advanced student writing than stances that are implicitly attitudinal, detached, and dialogically expansive, or open to other views in the surrounding discourse. Especially as students progress into upper-level writing in the disciplines, they are expected to project authorial personae that adjudicate, or juxtapose "other voices [that] are explicitly drawn into the discussion, interpreted, analyzed, critiqued, and played off against each other" (Derewianka, 2007, p.163). These findings have important implications for the ways we view students' emerging conceptualizations of knowledge making and of their readers. For instance, in terms of Hyland and Milton's (1997) study, carefully modulating between qualification and certainty can be seen in more dialogic terms as modulating between dialogical expansion and contraction, or opening up then closing down space for negotiating with alternative points of view. In a similar vein, language choices that index a critical or "competitive" epistemological stance, as discussed by Barton (1993), may also be thought of as resources used to contract the dialogic space at key moments in the discourse, "as the writer bids to win the reader over" (Martin \& White, 2005, p.125).

Other studies on rhetorical choices in academic writing genres across the soft-hard disciplines can mostly be found, just to name a few, in Hyland (1998, 2000, 2001, 2002, 2007, 2008) for academic research articles, in Hyland and Tse (2004a) and Yang (2012) for dissertation acknowledgements, in Yang (2013a) for academic textbook blurbs, in Yang (2013b) for academic calls for papers, and in Hyland and Tse (2009), Diani (2009), and Groom (2009) for book reviews. All of these studies exemplify how the different science disciplines make meanings and elucidate various contexts for interpretation with individual conventions within their disciplinary cultures (Hyland, 2004a).

\section{Methodology}

Two corpora were used for analysis in this descriptive-comparative study, which aimed at investigating and comparing the use of stance strategies in academic articles of native and nonnative writers in the domain of TEFL. In this section, the methodology employed to carry out the study is elaborated.

\subsection{Corpora}

Forty ISI articles (20 for American native and 20 for Iranian nonnative writers) were selected from System, TESOL Quarterly, ELT and IJAL (International Journal of Applied Linguistics) journals as the corpora for American native and Iranian nonnative writers. Iranian nonnative writers were quite easy to identify (through their names and affiliations); American native writers were also identified by means of their affiliations, and through email communication with them in cases where their identity and originality were not easily recognized.

\subsubsection{Corpus for American Native Writers}

The corpus which was used for American native writers, consisting of 20 research articles (as was mentioned above), included 11976 words, the stance strategies of which are provided below in Table 2. 


\section{International Journal of Research in English Education}

Table 2. Native writers

\begin{tabular}{ll}
\hline Attitude Markers & 39 \\
\hline Hedges & 41 \\
Boosters & 29 \\
Self-mention & 44 \\
\hline
\end{tabular}

\subsubsection{Corpus for Iranian Nonnative Writers}

The corpus which was used for Iranian nonnative writers was also composed of a score of research papers, the words of which amounted to a total number of 12354 words, and the stance strategies of which are provided in Table 3 below.

Table 3. Non- native writers

\begin{tabular}{ll}
\hline Attitude Markers & 27 \\
\hline Hedges & 29 \\
Boosters & 32 \\
Self-mention & 24 \\
\hline
\end{tabular}

\subsection{Data Collection Procedure}

The corpora deployed for the purpose of this study were purposefully selected; differently put, care was exerted to select and include in the corpora the papers authored by Iranian nonnative and American native writers exclusively. In cases of uncertainty, an email message would be sent to the author of the article to make certain about their country of origin. After decisions were made about the nationality/origin of the authors, their articles were examined for the number of words and also the number of stance markers; the number of exact words utilized in the given articles came to:
a. 11976 words for American native writers
b. 12354 words for Iranian nonnative writers

Despite the availability of such programs as Text Stat, Word Pilot, and Antconc, the words/stance markers were also detected and double-checked manually by the current researchers to ensure a higher degree of reliability. Different tokens of each type of markers were then tallied and recorded.

\subsection{Statistical Procedures}

In this corpus-based study, the corpora, upon data collection, were analyzed by SPSS, version 22 . It should be mentioned that first frequency and percentage of the materials were calculated, and then Chi-Square was run to make comparisons between the native and nonnative authors of those research articles.

\section{Results}

The analysis of the introduction and discussion sections are in line with Hylands (2005) stance and engagement model.

The results of the study are illustrated in Table 4. 


\section{International Journal of Research in English Education}

Table 4. Stance strategies frequency and percentage of non-native and native English academic writers

\begin{tabular}{|c|c|c|c|c|c|c|}
\hline Stance & & & Frequency & Percent & Valid Percent & $\begin{array}{l}\text { Cumulative } \\
\text { Percent }\end{array}$ \\
\hline \multirow[t]{3}{*}{ Attitude Markers } & Valid & Native Writers & 39 & 59.1 & 59.1 & 59.1 \\
\hline & & N-Native Writers & 27 & 40.9 & 40.9 & 100.0 \\
\hline & & Total & 66 & 100.0 & 100.0 & \\
\hline \multirow[t]{3}{*}{ Hedges } & Valid & Native Writers & 41 & 58.6 & 58.6 & 58.6 \\
\hline & & N-Native Writers & 29 & 41.4 & 41.4 & 100.0 \\
\hline & & Total & 70 & 100.0 & 100.0 & \\
\hline \multirow[t]{3}{*}{ Boosters } & Valid & Native Writers & 29 & 47.5 & 47.5 & 47.5 \\
\hline & & N-Native Writers & 32 & 52.5 & 52.5 & 100.0 \\
\hline & & Total & 61 & 100.0 & 100.0 & \\
\hline \multirow[t]{3}{*}{ Self-mention } & Valid & Native Writers & 44 & 64.7 & 64.7 & 64.7 \\
\hline & & N-Native Writers & 24 & 35.3 & 35.3 & 100.0 \\
\hline & & Total & 68 & 100.0 & 100.0 & \\
\hline
\end{tabular}

As shown in the above table, the frequency of attitude-markers of non-native writers is 27 (40.9\%), while it is 39 for natives accounting for $59.1 \%$. On the other hand, the frequency of hedges for natives was $41(58.6 \%)$ while nonnatives frequency was $29(41.4 \%)$. Natives result for booster was 29 (47.5) and for non-natives 32 (52.5). As for selfmentions, native speakers deployed such strategies twice more those of non-natives forming 35.5\%. For the sake of clarity, the results of Table 4 are depicted in Figure 1. 


\section{International Journal of Research in English Education}

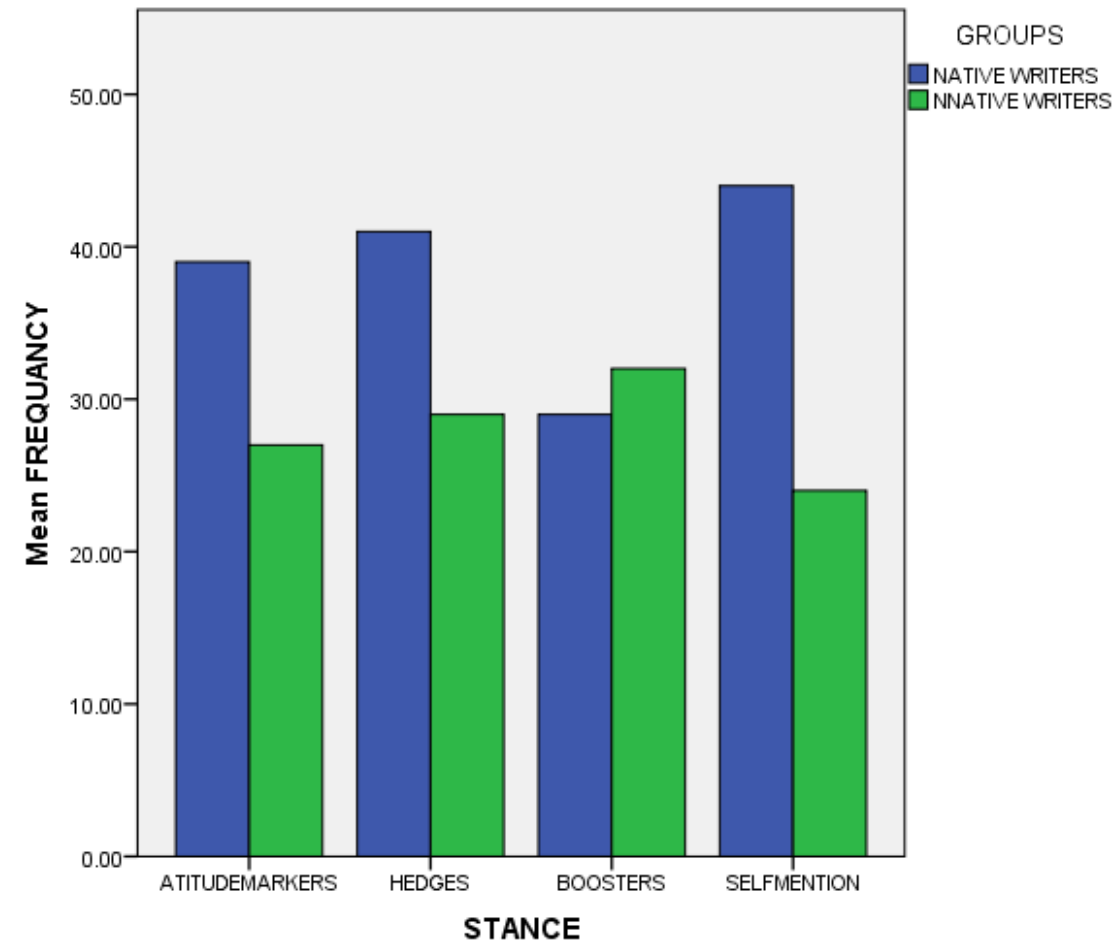

Figure 1. Frequency of stance strategies of native and non-native academic writers

As reveled by the graph, with regard to how frequently attitude-markers, hedges, and self-mentions were utilized, native writers used more items than non-natives. Native writers, however, made use of boosters less than non-natives.

The second research question posed in this study was "Is there any significant proportion between Iranian and American M.A EFL writers in using stance strategies (Hedges, Boosters, Attitude markers, and Self mentions) in Introduction and Discussion sections of the academic papers? To test its corresponding null hypothesis, a Chi-Square test was run to determine if native writers had used a different number of stance strategies in the introduction and discussion sections of their research articles. The obtained results (see Table 5) revealed that there was not a statistically significant difference between native and non-native writers in using stance strategies in the introduction and discussion sections.

Table 5. Chi-square analysis of stance strategies of native and non-native writers

\begin{tabular}{lccc}
\hline & Value & $d f$ & Asymp. Sig. (2-sided) \\
\hline Pearson Chi-Square & 4.022 & 3 & .259 \\
Likelihood Ratio & 4.010 & 3 & .260 \\
Linear-by-Linear Association & .068 & 1 & .794 \\
N of Valid Cases & 265 & \\
\hline
\end{tabular}




\section{International Journal of Research in English Education}

As it could be seen in Table 5, Pearson Chi-Square value and the degree of freedom for native writers is 4.022 and 3 respectively and also $\mathrm{p}$ value in turn is shown to be .259 . This leads us to the conclusion that there is not a significant proportion between native and non-native writers in using stance strategies within academic papers. The results of this study are also presented in Figure 2.

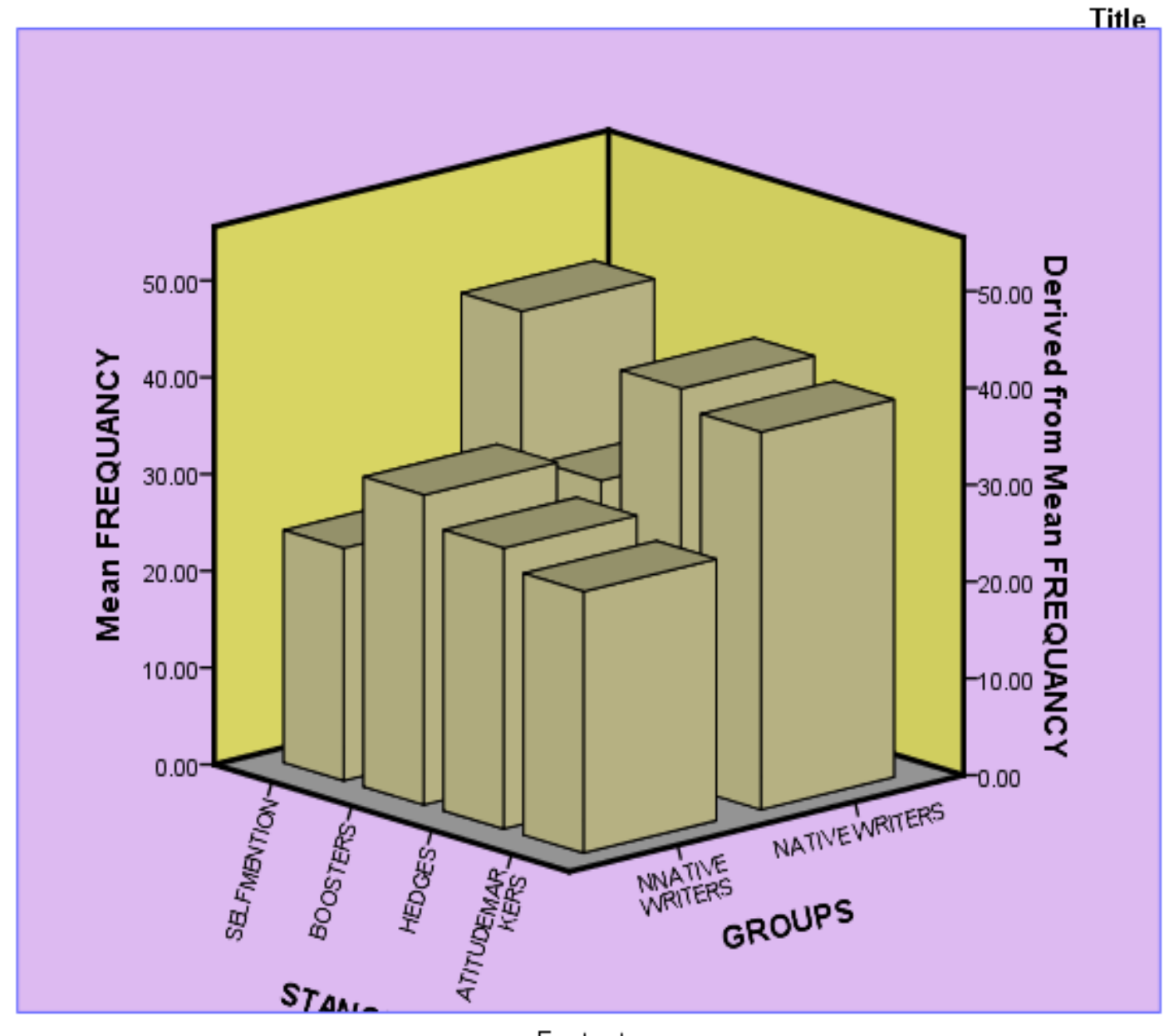

Footnote

Figure 2. The overall graphic representation of stance strategies of native and non-native writers in academic articles

\section{Discussion}

As mentioned before, the main objective of this study was to give a comprehensive account of the differences in using stance strategies with respect to Introduction and Discussion sections of academic articles, adopting the theorized framework of Hyland (2005). The first research question for this study was: What is the frequency and percentage of stance strategies (hedges, boosters, attitude markers, and self-mentions) in the research articles of American native and Iranian nonnative writers. By considering the results of descriptive analysis (frequency and percentage) in Table 4 , it could be concluded that native writers' frequencies of attitude markers, hedges, and self-mentions were more than nonnative writers, but the native writers' frequencies of boosters were fewer than nonnative writers' percentages. 


\section{International Journal of Research in English Education}

The second research question was investigated by analyzing the results of inferential statistics obtained from the Chisquare test in Table 5. No statistically significant difference was found in terms of using stance strategies between native and nonnative writers. In addition, it was concluded that native writers employed hedges, attitude markers, and self-attitude markers more frequently than nonnative writers. In contrast, nonnative writers, though not significantly different, made more use of boosters than other strategies.

The overall findings of this study support Blagojevic's (2004) study who investigated the differences between English native and nonnative speakers in that the results of the current study also indicated no statistically significant difference in use of metadiscourse markers across the given disciplines. In addition, Rashidi and Alihosseini's (2012) study examined the difference in the use and frequency of metadiscourse markers in the abstracts of 20 research articles in the field of sociology and engineering. The obtained results revealed no statistically significant difference in the use of metadiscourse markers across the selected disciplines lending further weight to the current study. The current study is not in line with Atai and Sadr's (2008) study as their findings showed a statistically significant difference in the use of hedging markers in the academic writings of English native and nonnative speakers in applied linguistics research studies.

Moreover, Abdi's (2002) study on the type and application of MDMs (meta-discourse markers: hedges, emphatics, and attitude-markers) in two different majors revealed a statistically significant difference between the majors where SS writers used MDMs in a different amount and type. Another study which ran counter to our current study was conducted by Ansarian and Tarlani (2011). The results of their study showed significant differences in the way native Persian and English writers represent their readers. Also, considerable differences were observed in categorical distribution of reader engagement markers (Ansarian \& Tarlani, 2011).

The conflicting results of the above-mentioned studies could be accounted for owing to sociocultural aspects of writers which are highly likely to affect their voice and interaction. In other words, because of actual context exposure which in turn impacts the degree of aplomb, native writers tend to use stance strategies such as self-mentions more frequently than nonnatives. This is not unlike the way advocates of Hallydaian linguistics give a thorough account of sociolinguistics factors in domain of contrastive analysis. In addition, the educational setting in Iranian system of education can have some bearing on it as learners have not learned to assume responsibility for their own learning. This may well lead to a situation where nonnative writers are less apt to have recourse to such strategies.

\section{Conclusion}

Conveying the voice of writers is very important within international orthographic frameworks. The academic writers should follow a very rich and powerful paradigms to put more emphasis on their findings. To gain this end they need to improve the genre and style of their writings. One of the most important aspects to arrive at this point is to apply appropriate stance and engagement strategies in writings. The findings of this study revealed that native writers made more use of attitude markers, hedges, and self-mentions vis-à-vis nonnative writers, while the latter groups of writers tended to use boosters more frequently than the former group of writers. The overall difference between the native and nonnative writers with respect to the frequency of use of different types of stance markers failed to be of statistical significance. These obtained results could help writers to understand this fact that if they follow standard and appropriate discourse markers in their papers and scientific articles they will gain better results. English teachers could use the findings of this study by applying them in their classes to teach their students how to convey their voice through standard writing. Another application of the results of this study is connected with ESP (English for Specific Purposes). Today the language of science is English in all majors. Experts from different nations with different nationalities tend to publish their studies in English; if they use stance strategies in an appropriate manner, chances are that their findings will reach the corners of the world more vividly and comprehensibly.

\section{References}

Abdi, R. (2002). Interpersonal metadiscourse: An indicator of interaction and identity. Discourse Studies, 4(2), 139145. doi: $10.1177 / 14614456020040020101$

Ansarian, A. A., \& Tarlani-Aliabdi, H. (2011). Reader engagement in English and Persian applied linguistics articles. English Language Teaching, 4(4), 154-164. doi: 10.5539/elt.v4n4p154 


\section{International Journal of Research in English Education}

Atai, M., \& Sadr, L. (2008). A cross-cultural genre study on hedging devices in discussion section of applied linguistic research articles. Journal Teaching English Language and Literature Society of Iran, 7(2), 42-57.

Barton, E. (1993). Evidentials, argumentation, and epistemological stance. College English, 55(7), 745-769. doi: $10.2307 / 378428$

Blagojevic, S. (2004). Metadiscourse in academic prose: A contrastive study of academic articles written in English by English and Norwegian native speakers. Studies about Linguistics, 5(1), 1-7. doi: 10.3726/978-3-03510901-6/7

Coffin, C. (2002). The voices of history: Theorizing the interpersonal semantics of historical discourses. Text, 22(4), 503-528. doi: 10.1515/text.2002.020

Conrad, S., \& Biber, D. (2000). Adverbial Marking of Stance in Speech and Writing, Evaluation in Text: Authorial Stance and the Construction of Discourse, Oxford, Oxford University Press.

Derewianka, B. (2007). Using appraisal theory to track interpersonal development in adolescent academic writing. In A. McCabe, M. O’Donnell, \& R. Whittaker, R. (Eds.), Advances in language and education (pp. 142-165). New York and London: Continuum.

Diani, G. (2009). Reporting and evaluation in English book review articles: A crossdisciplinary study. In K. Hyland \& G. Diani (Eds.), Academic evaluation: Review genres in university settings (pp. 105-121). Basingstoke: Palgrave MacMillan.

Groom, N. (2009). Phraseology and epistemology in academic book reviews: A corpus-driven analysis of two humanities disciplines. In K. Hyland \& G. Diani (Eds.), Academic evaluation: Review genres in university settings (pp. 122-142). Basingstoke: Palgrave MacMillan.

Halliday, M. A. K. (1994). An introduction to functional grammar. London: Edward Arnold.

Hansen, C. (1994). Topic identification in lecture discourse. In J. Flowerdew (Ed.), Academic listening, Research perspectives (pp. 131-145). Cambridge: Cambridge University Press.

Hewings, A. (2004). Developing discipline-specific writing: An analysis of undergraduate geography essays. In L. J. Ravelli \& R. A. Ellis (Eds.), Analysing academic writing: Contextualized frameworks (pp. 131-152): Continuum.

Holmes, J. (1984). Modifying illocutionary force. Journal of Pragmatics, 8, 345-365.

Holmes, J. (1990). Hedges and boosters in women's and men's speech. Language \& Communication, 10(3), $185-205$.

Hunston, S., \& Thompson, G. (2000). Evaluation in text. Oxford: Oxford University Press.

Hyland, K., \& Milton, J. (1997). Qualification and certainty in L1 and L2 students' writing. Journal of Second Language Writing, 6(2), 183-205. doi: 10.1016/s1060-3743(97)90033-3

Hyland, K. (1998). Boosting, hedging and the negotiation of academic knowledge. Text \& Talk, 18(3), $349-382$. doi: https://doi.org/10.1515/text.1.1998.18.3.349

Hyland, K. (1999). Disciplinary discourse: Writer stance in research article. In C. Candlin \& K. Hyland (Eds.), Writing: Texts, processes and practices (pp. 99-121). London: Longman.

Hyland, K. (2000). Disciplinary discourses: Social interactions in academic writing. London: Longman.

Hyland, K. (2001). Bringing in the Reader: Addressee Features in Academic Writing. Written Communication, 18(4), 549-74.

Hyland, K. (2001). Humble servants of the discipline? Self-mention in research articles. English for Specific Purposes, 20(3), 207-26. doi: 10.1016/s0889-4906(00)00012-0

Hyland, K. (2002). Options of identity in academic writing. ELT Journal, 56(4\&1), 351-358. https://doi.org/10.1093/elt/56.4.351 


\section{International Journal of Research in English Education}

Hyland, K. (2004a). A convincing argument: Corpus analysis and academic persuasion. In U. Connor \& Upton, T. A. (Eds.), Discourse in the professions: Perspectives from corpus linguistics (pp. 87-112). Amsterdam: John Benjamins.

Hyland, K. (2005). Stance and engagement: A model of interaction in academic discourse. Discourse Studies, 7(2), 173-192. doi: 10.1177/1461445605050365

Hyland, K. (2007). Different strokes for different folks: Disciplinary variation in academic writing. In K. Flottum (Ed.), Language and Discipline Perspectives on Academic Discourse (pp. 89-108). Newcastle: Cambridge Scholars Publishing.

Hyland, K. (2008). As can be seen: Lexical bundles and disciplinary variation. English for Specific Purposes, 27(1), 4-21. Doi:10.1016/j.esp.2007.06.001

Hyland, K., \& Tse, P. (2004a). I would like to thank my supervisor: Acknowledgements in graduate dissertations. International Journal of Applied Linguistics, 14(2), 259-275. doi:10.1111/j.1473-4192.2004.00062.x

Hyland, K., \& Tse, P. (2009). Discipline and gender: Constructing rhetorical identity in book reviews. In K. Hyland \& G. Diani (Eds.), Academic evaluation: Review genres in university settings (pp. 87-104). Basingstoke: Palgrave MacMillan.

Martin, J. R., \& White, P. R. R. (2005). The language of evaluation: Appraisal in English. London, UK: Palgrave Macmillan.

Myers, G. (1989). The pragmatics of politeness in scientific articles. Applied Linguistics, 10(1), 1-35. https://doi.org/10.1093/applin/10.1.1

North, S. (2005). Disciplinary variation in the use of theme in undergraduate essays. Applied Linguistics, 26(3\&1), 431-452. https://doi.org/10.1093/applin/ami023

Rashidi, N., \& Alihosseini, F. (2012). A contrastive study of metadiscourse markers in research article abstracts across disciplines. Bulletin of the Transilvania University of Brasov, 5(4), 17-23.

Salager-Meyer, F. (1994). Hedges and textual communicative function in medical English written discourse. English for Specific Purposes, 13(2), 149-70.

Salager-Meyer, F. (1997). I think that perhaps you should: A study of hedges in written scientific discourse. In T. Miller(Ed.), Functional approaches to written text: Classroom applications. Washington, D.C: United States Information Agency.

Swales, J. (1990). Genre Analysis: English in academic and research settings. Cambridge: CUP.

Van Dijk, T. A. (1998). Ideology. A Multidisciplinary Approach. London: Sage.

Yang, W. H. (2012). A genre analysis of PhD dissertation acknowledgements across disciplinary variations. LSP Journal, 3(2), 51-69. doi: 10.7575/ijalel.v.1n.5p.130

Yang, W. H. (2013a). Keyness in academic textbook blurbs: Lexical variations across disciplines. 2012 Proceedings of English Learning and Teaching (pp.63-72). Pingtung, Taiwan: National Pingtung University of Science and Technology.

Yang, W. H. (2013b). Two-folded messages behind CFP: A cross disciplinary examination. International Journal of Language Studies, 7(2), 83-108. 